\title{
Ventilation to maintain indoor air quality in smoking rooms
}

\author{
D. G. Snelson, H. Al-Madfai \& A. J. Geens \\ Faculty of Advanced Technology, University of Glamorgan, UK
}

\begin{abstract}
A number of legislative bodies in Europe have already made or are currently considering making policy decisions on the issue of smoking in public places. Policy alternatives have been discussed in Town and Country Planning. Scientific evidence relating to this debate has been reported in a diverse range of publications such as the British Medical Journal, Indoor Air and The Chartered Institution of Building Services Engineers Journal. On inspection much of this reporting concludes negatively on the performance of ventilation systems. This paper uses a case study, Jack Bailey's public house in Wexford (high level supply and extract ventilation system), to demonstrate the effectiveness of a ventilation system in dealing with ETS that could be achieved in smoking rooms by monitoring a solid (PM 2.5), and a gaseous $\left(\mathrm{CO}\right.$ and $\left.\mathrm{CO}_{2}\right)$ constituent.
\end{abstract}

Keywords: ventilation, environmental tobacco smoke (ETS), smoking rooms, indoor air quality, legislation.

\section{Introduction}

A number of legislative bodies in Europe have already made or are currently considering making policy decisions on the issue of smoking in public places. Policy alternatives have been discussed in Town and Country Planning [1]. Scientific evidence relating to this debate has been reported in a diverse range of publications such as the BMJ, Indoor Air and the CIBSE Journal. On inspection much of this reporting concludes negatively on the performance of ventilation systems [2-4].

In Wales the smoking ban has allowed a number of exemptions, and it is important that these spaces are ventilated using the best techniques available in order to protect both user groups and staff employed in these buildings for 
example residential care homes, hospices and mental health units where patients are held in secure conditions for more than six months [5]. The most immediate health and safety concern from smoking in this type of building is probably that of fire with the risk of smokers falling asleep in their rooms whilst smoking. This risk is reduced by providing a smoking room which is more easily monitored than individual rooms. The same strategy facilitates easier management of longer term health and safety concerns about the exposure of staff to environmental tobacco smoke (ETS). The use of ventilation to prevent migration of ETS through the building and to dilute ETS in the smoking room is more easily and economically managed if smoking is limited to one room. Ironically, many in the medical profession have dismissed the role of ventilation in limiting exposure to ETS in their campaign for the introduction of smoking bans, although this debate has highlighted the case that many hospitality venues do not use ventilation systems effectively, and that not all ventilation systems are equally effective. Ventilation systems are now being installed in hospitality venues to reduce smells that were originally masked by the tobacco smoke after the smoking ban came into force for example body and food odours.

As a result of the negative reporting on ventilation in the debate leading up to the introduction of the ban, there is a possibility that the potential contribution from ventilation systems in managing such risks may be ignored. It would appear that the UK government unquestioningly accepted the argument that adequately ventilated rooms were not an alternative to a complete ban. Consequently it is now difficult for the government to offer advice to exempt building operators on how to ventilate their buildings to comply with Health and Safety requirements. Many of these buildings are government controlled and regulated. A case study, Jack Bailey's public house in Wexford (high level supply and extract ventilation system), is used to demonstrate the effectiveness of a ventilation system in dealing with ETS that could be achieved in smoking rooms by monitoring a solid (PM 2.5), and a gaseous (CO) constituent.

\subsection{Regulatory framework for ventilations in buildings}

Buildings should be adequately ventilated as defined by the Buildings Regulations 2000, Part F [7]. In 2003 Geens [6] began a series of ventilation effectiveness surveys of new or upgraded ventilation systems installed in pubs that had been designed to provide improved air quality, specifically in the bar serving area, but for the whole building as a consequence. The ventilation system would reduce the exposure concentrations of environmental tobacco smoke (ETS) of employees and smokers. The airborne contaminants that were measured can be harmful in high concentrations. The levels of acceptable worker exposure are set out in Workplace Exposure Limits [8] set by the Health and Safety Executive (HSE). The Health and Safety Executive [8] recommended maximum exposures for industrial environments developed by Health and Safety Commission, which is responsible for health and safety regulation in the United Kingdom. Levels and limits (Table 1), which are regularly reviewed and updated, are enforceable in the United Kingdom (UK) and are not selected to protect the most sensitive individuals. 
Table 1: $\quad$ UK indoor air quality.

\begin{tabular}{|c|c|c|}
\hline & HSE \\
\hline & & UK \\
\hline Carbon Dioxide & $\mathrm{CO}_{2}$ & $5000 \mathrm{ppm}$ \\
\hline Carbon Monoxide & $\mathrm{CO}$ & $30 \mathrm{ppm}$ \\
\hline Respirable Particles $<2.5 \mu \mathrm{m}$ & PM 2.5 & $4 \mathrm{mg} / \mathrm{m}^{3}$ \\
\hline
\end{tabular}

Also The European Standard EN 13779:2004 (E) [9] further sets out a basic classification for indoor air quality (IDA) based upon the average level of carbon dioxide (Table 2) in the air over an 8 hour period.

Table 2: $\quad$ European indoor air quality.

\begin{tabular}{||c|c|c||}
\hline \hline Category & Description & $\begin{array}{c}\mathrm{CO}_{2} \text { level in room (above } \\
\text { ambient external) }\end{array}$ \\
\hline IDA 1 & High indoor air quality & $<400 \mathrm{ppm}$ \\
\hline IDA 2 & Medium indoor air quality & $400-600 \mathrm{ppm}$ \\
\hline IDA 3 & Moderate indoor air quality & $600-1000 \mathrm{ppm}$ \\
\hline IDA 4 & Low indoor air quality & $>1000 \mathrm{ppm}$ \\
\hline
\end{tabular}

\section{Methodology}

The Jack Bailey's Public House situated Wexford; Southern Ireland had a ventilation effectiveness study carried out from 18.00 on Thursday $4^{\text {th }}$ till 10.00 Saturday $6^{\text {th }}$ September 2003. The public area is arranged as three interconnecting rooms and is located on the outskirts of Wexford City. The total floor area is approximately $133 \mathrm{~m}^{2}$ but measurements were taken in the bar (see figure 1). This has a floor area of $48 \mathrm{~m}^{2}$. The pub has an installed conventional (high level supply and extract) ventilation system providing 12-15 air changes per hour.

\subsection{Measurements of environmental tobacco smoke (ETS)}

The sampling devices used in this study were the Dustrak Aerosol Monitor Model 8520 by TSI Inc, using the $2.5 \mu \mathrm{m}$ inlet conditioner and a flow rate of 1.7 1/min, and the Q-Trak Plus IAQ Monitor Model 8554 by TSI Inc. The sampling devices were located in the bar serving area at a height approximating to the breathing zone. During the busy periods an hourly cigarette count was taken. Levels of carbon dioxide, carbon monoxide and respirable suspended particles (PM 2.5), were recorded. Although other markers have been used in other studies, the selection of markers is actually unimportant when assessing ventilation performance, as according to Dalton's Law of Partial Pressure [10]:

"A gas mixture behaves in exactly the same fashion as a pure gas" 
The ventilation equipment was turned off during Thursday evening $\left(4^{\text {th }}\right.$ September). Continuous real-time monitoring was carried out to ensure that peak exposure conditions were captured and to measure baseline levels of markers during the overnight period of no occupancy.

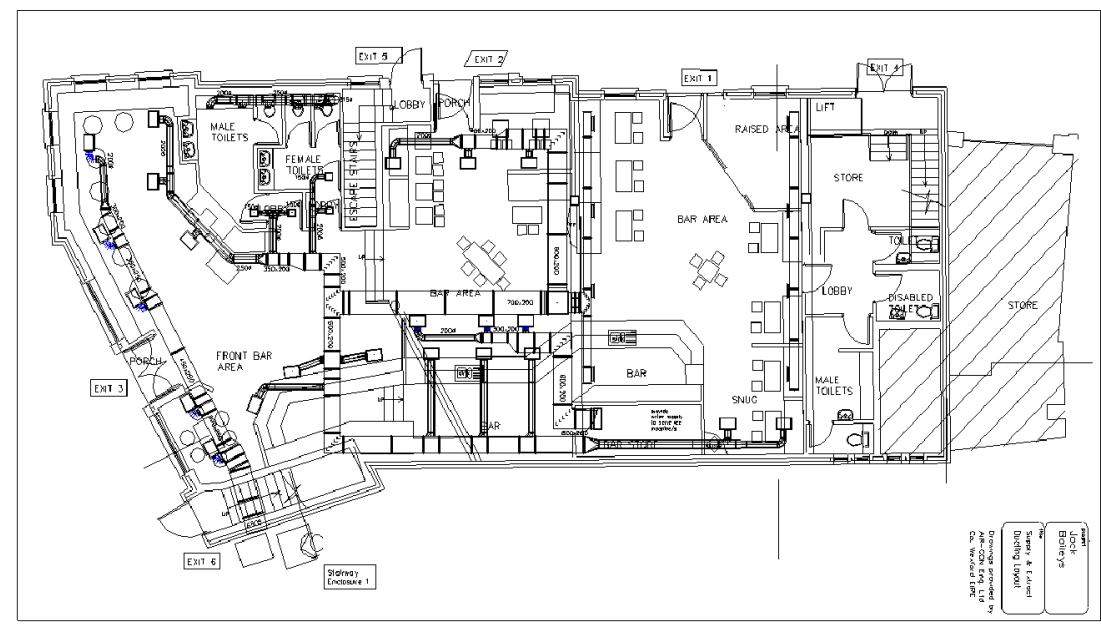

Figure 1: $\quad$ Layout of Jack Bailey’s Public House.

\subsubsection{Respirable suspended particles}

Respirable suspended particles (PM 2.5) are a constituent of environmental tobacco smoke (ETS) and serve as a marker. The long-term exposure limit (8 hour time weighted average) for respirable particles is $4 \mathrm{mg} / \mathrm{m}^{3}$ [8]. However, figures for traffic related airborne particles currently under review by DEFRA suggest annual exposure limits of a mean value of $0.04-0.05 \mathrm{mg} / \mathrm{m}^{3}$. It should be noted that this figure relates to "fresh air" rather than indoor air and is an annual rather than an 8 hour average.

\subsubsection{Carbon monoxide}

Carbon monoxide (CO) is a constituent of ETS but is sometimes considered unsuitable as an ETS marker, as it has other sources such as gas fires. The advantages of ease of real-time recording and the existence of recognised occupational exposure standards for $\mathrm{CO}$ outweighed this concern. Additionally any $\mathrm{CO}$ from other sources will make the test conditions more onerous, not less. The long-term exposure limit ( 8 hour time weighted average) for carbon monoxide is 30 parts per million [8].

\subsubsection{Carbon dioxide}

Carbon dioxide $\left(\mathrm{CO}_{2}\right)$ is a product of respiration and occurs naturally in the atmosphere. It is therefore usual to use as an indication of the effectiveness of the ventilation system in occupied buildings. For the purposes of this study it is important to establish that the ventilation is performing effectively. A figure of $12000 \mathrm{ppm}$ is identified by the World Health Authority as the level of concern 
[8]. This is very unlikely to be reached in a building in normal occupation. The long-term exposure limit ( 8 hour time weighted average) for Carbon Dioxide is $5000 \mathrm{ppm}$ [8]. For comfort and adequate odour dilution, a $\mathrm{CO}_{2}$ level of $1000 \mathrm{ppm}$ is recommended. It is also worth noting that $\mathrm{CO}_{2}$ is present in fresh air at around $400 \mathrm{ppm}$ and so, unlike other indicators, $\mathrm{CO}_{2}$ will not tend towards zero.

\subsection{Cigarette count}

The number of cigarettes consumed was measured on an hourly basis through a count of the cigarette butts collected in ashtrays to produce a measure of cigarettes/hour. To gain a fair comparison with other studies in venues of different sizes the cigarette count has been divided by the volume of the premises, to provide a measure of cigarettes $/ \mathrm{m}^{3} /$ hour.

\subsection{Ventilation system turned off}

When customers were smoking heavily the ventilation system was turned off for approximately 10 minutes. This was to simulate conditions prior to the installation of the new system and to illustrate the effectiveness of the ventilation system on air quality inside the premises.

\section{Results}

\subsection{Carbon monoxide}

The results of the monitoring for $\mathrm{CO}$ can be seen in Figures 2, 3 and 7. These results (Figure 7) indicate that levels overnight fall to ambient levels in fresh air, $0 \mathrm{ppm}$. Figure 1 shows that when the ventilation is switched off contamination steadily rises to a peak of $6.5 \mathrm{ppm}$. Figure 2 shows that when the ventilation is run continuously, the $\mathrm{CO}$ levels are detected at a resolution of $0.1 \mathrm{ppm}$. The workplace exposure limit noted above is an average of 30 ppm over an eighthour period.

\subsection{Carbon dioxide}

The results of the monitoring for $\mathrm{CO}_{2}$ can also be seen in Figures 2, 3 and 6 . These results (Figure 6) indicate that $\mathrm{CO}_{2}$ levels overnight very quickly fall to ambient levels in fresh air, (around $350 \mathrm{ppm}$ ), as would be expected. Figure 2 shows that with the ventilation off $\mathrm{CO}_{2}$ rises to over $2200 \mathrm{ppm}$ before customer complaints caused the ventilation to be switched on again. Once the ventilation is reinstated the $\mathrm{CO}_{2}$ level quickly falls to $700 \mathrm{ppm}$ even though this was the period of peak occupancy. Figure 3 demonstrates that when the ventilation is switched on and run continuously the $\mathrm{CO}_{2}$ is limited to a maximum of $750 \mathrm{ppm}$ even when the outlet is very busy. The workplace exposure limit noted above is an average of $12000 \mathrm{ppm}$ over an eight-hour period as a cause for concern and $1000 \mathrm{ppm}$ being the accepted level for comfort and odour control. 


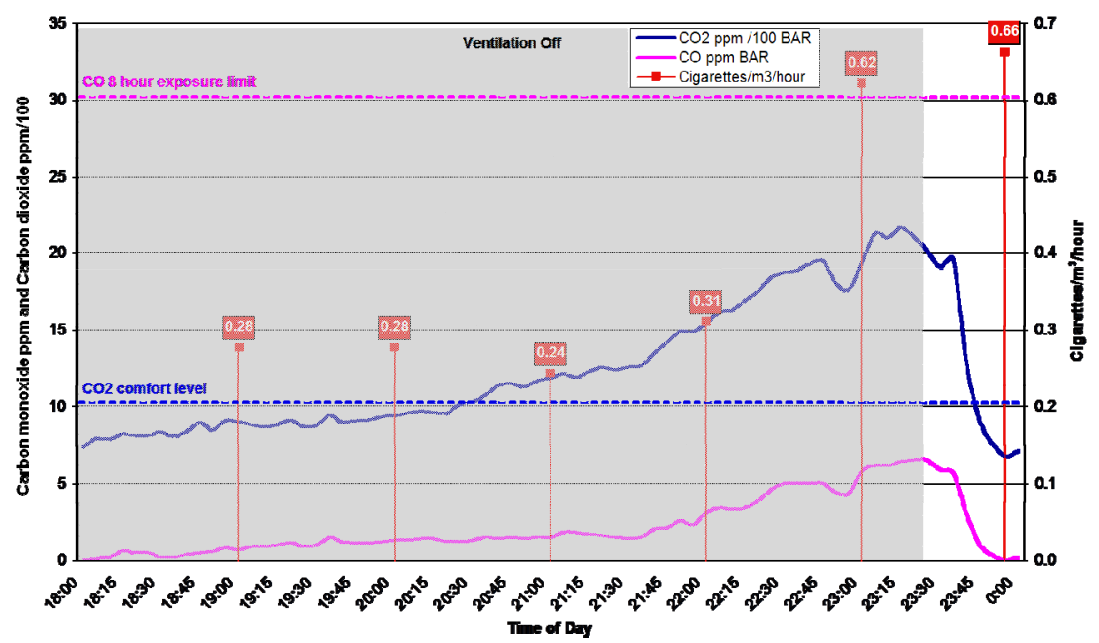

Figure 2: Jack Bailey's public house carbon monoxide /carbon dioxide Thursday $4^{\text {th }}$ September 2003.

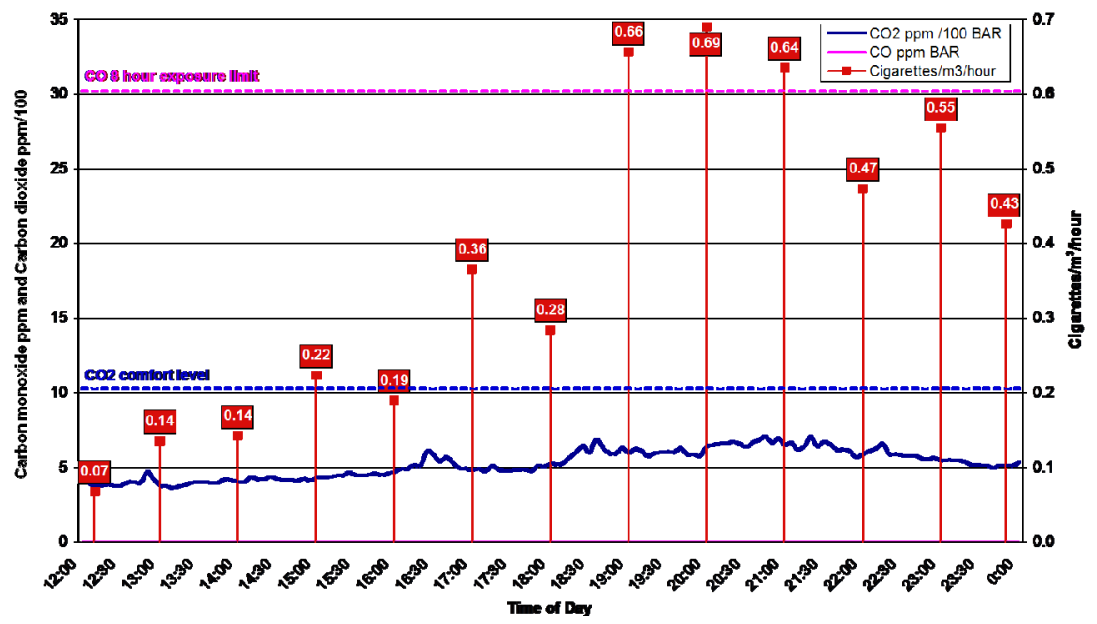

Figure 3: Jack Bailey's public house carbon monoxide /carbon dioxide Friday $5^{\text {th }}$ September 2003.

\subsection{Respirable suspended particles}

The results for the monitoring for PM 2.5 can be seen in Figures 4, 5 and 7. These results show that particle levels overnight fall to values below $0.1 \mathrm{mg} / \mathrm{m}^{3}$ (Figure 7). Figure 5 show that the ventilation controls the rise in particle levels to $1.3 \mathrm{mg} / \mathrm{m}^{3}$. Figure 4 shows that when the ventilation is out of service, the particle levels rise, on this occasion to over $6 \mathrm{mg} / \mathrm{m}^{3}$, but when the ventilation is reinstated, the readings return very quickly to their earlier levels. 


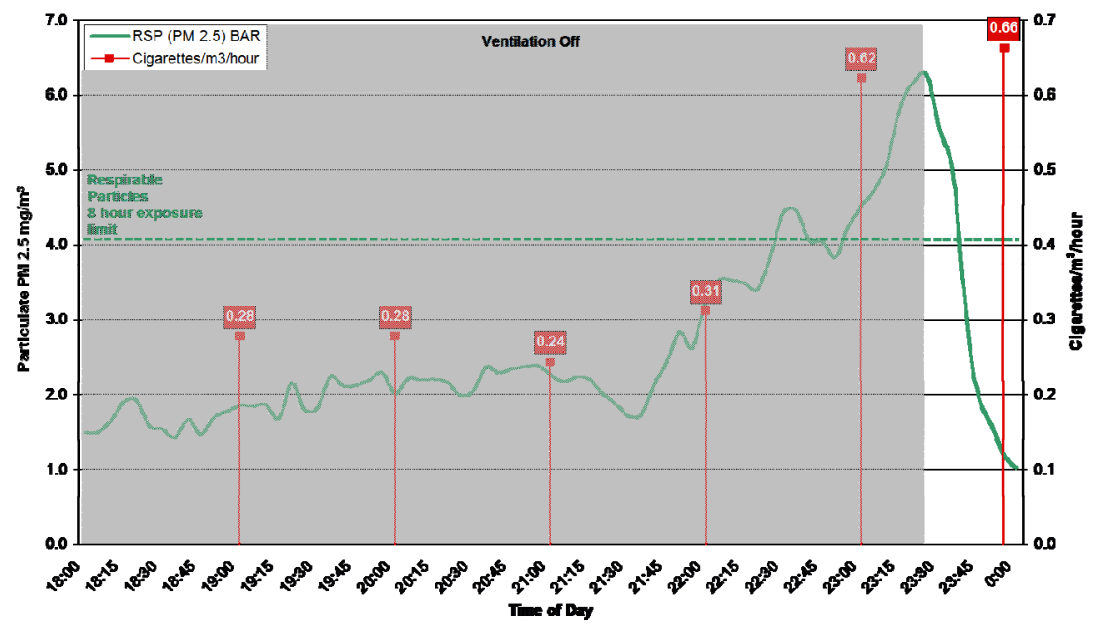

Figure 4: Jack Bailey's public house particulates (PM2.5) Thursday $4^{\text {th }}$ September 2003.

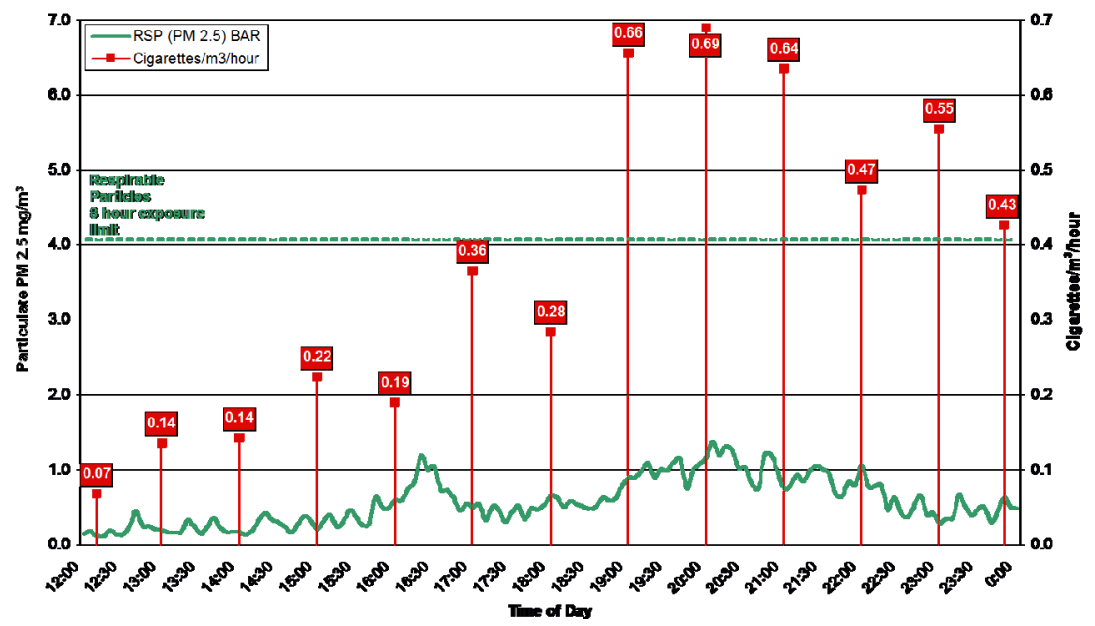

Figure 5: Jack Bailey's public house particulates (PM2.5) Friday $4^{\text {th }}$ September 2003.

\subsection{Cigarette count}

The level of smoking in Jack Bailey's was the highest that has been encountered in this series of studies carried out by the authors with 102 cigarettes being smoked in one hour (7-8 pm on Friday evening). This intense smoking was compounded by the limited size of the room to produce a smoking rate of 0.60 cigarettes $/ \mathrm{m}^{3} /$ hour (Figure 3 ). 


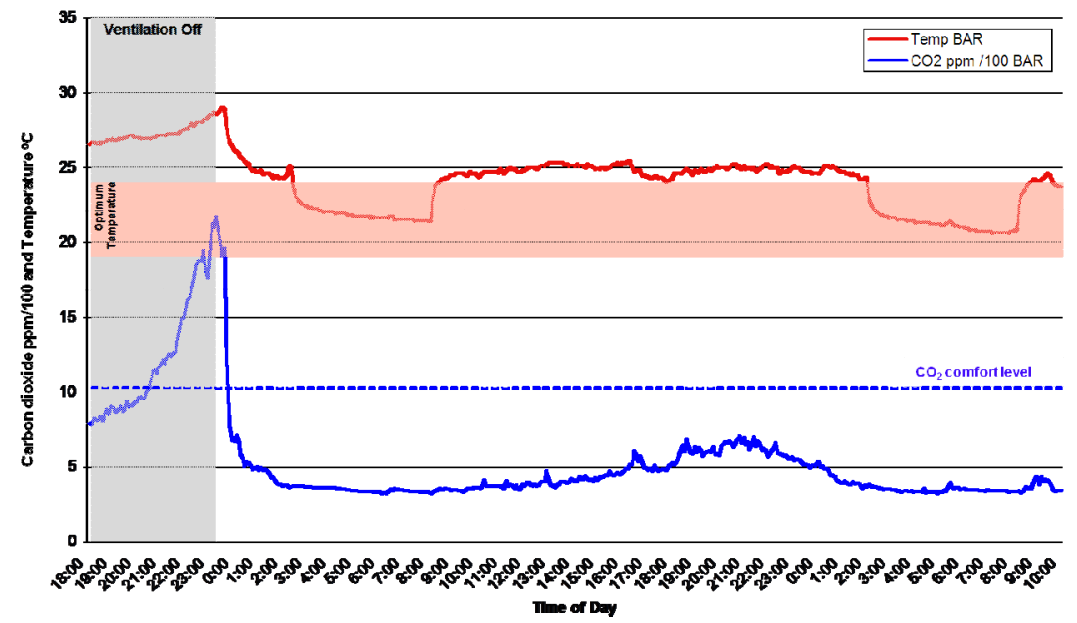

Figure 6: Jack Bailey's public house carbon dioxide Thursday $4^{\text {th }}$ till Saturday $6^{\text {th }}$ September 2003.

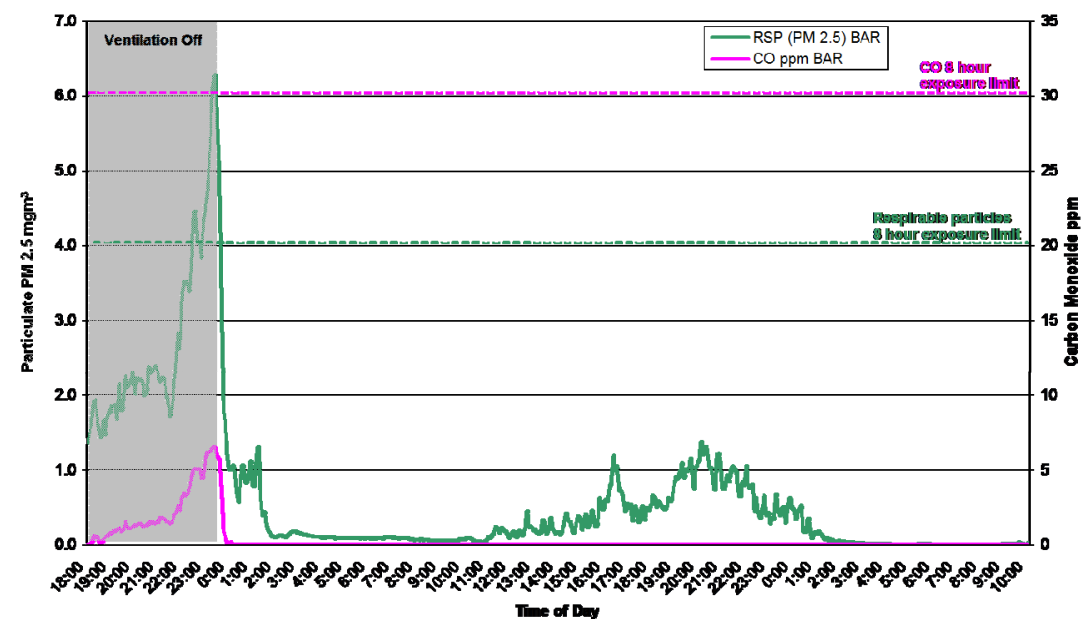

Figure 7: Jack Bailey's public house carbon monoxide and particulate (PM 2.5) Thursday $4^{\text {th }}$ till Saturday $6^{\text {th }}$ September 2003.

\subsection{Analysis of results}

When the ventilation was turned on towards the end of the evening the hourly cigarette count indicated that between $10 \mathrm{pm}$ and midnight $\left(4^{\text {th }}\right.$ September), smoking levels were consistently high at over ninety for each hour $(0.62$ and 0.66 cigarettes $/ \mathrm{m}^{3} /$ hour). In the absence of ventilation the concentrations of all three recorded markers were rising steadily and when the ventilation was turned 
on a very steep decay for both gases and particulate was observed (Figures 2 and 4). The fact that the three recorded markers, both solid and gaseous, responded in the same way suggests that the ventilation would have the same impact on other constituents of ETS (see section 2.1).

\section{Conclusion}

This study clearly demonstrates the ability of the ventilation system in a room to limit and control the concentrations of the ETS. The results (measurement of $\mathrm{CO}, \mathrm{CO}_{2}$ and PM2.5) from this study add weight to the argument that appropriately designed ventilation systems, significantly improve the air quality in rooms where smoking is taking place, meeting all available Health and Safety Executive Occupational Exposure Limits. This would reduce the exposure of both smokers and staff employed in residential care homes, hospices and mental health units where patients are held in secure conditions for more than six months. In 2008, a Scottish healthcare trust installed a balanced supply and extract ventilation system with heat recovery to prevent significant amounts of heat being lost to the outside air. These systems were installed in designated smoking rooms across the trust's semi-secure and open mental health units on seven sites. The units were chosen for their innovative heat recovery design and provided by an engineering company, which has also been involved in developing design solutions specifically to address the presence of smokers.

\section{References}

[1] Jones, P., Geens, A. J., Hillier, D. and Comfort, D., Smoking in public places. Town and Country Planning, 73, pp. 328 - 330, 2004.

[2] Carrington, J., Watson, A. F. R. and Gee, I. L., The effect of smoking status and ventilation on environmental tobacco smoke concentrations in public areas of UK pubs and bars. Atmospheric Environment, 37, pp. 3255 - 3266, 2003.

[3] Kotzias, D., Geiss, O., Leva, P., Bellintani, A. and Arvanitis, A., Impact of Various Air Exchange Rates on the Levels of Environmental Tobacco Smoke (ETS) Components. Fresenius Environmental Bulletin, 13, (12b), pp. $1536-1549,2004$.

[4] Gee, I. L., Watson, A. F. R., Carrington, J., Edwards, P.R., van Tongeren, M., McElduff, P. and Edwards, R. E., Second-hand smoke levels in UK pubs and bars: do the English Public Health White Paper proposals go far enough?. Journal of Public Health Medicine, 28, pp. 17 - 23, 2006.

[5] Geens, A., Breath of fresh air. Nursing Standard, 22, (20), pp. 22 - 23, 2008.

[6] Geens, A., Ventilation Effectiveness study at “Jack Bailey's Public House, Wexford" University of Glamorgan Commercial services, Report No. C8012B, 2003.

[7] Building Regulations 2000, Approved Document F - Ventilation (2006 edition), $3^{\text {rd }}$ May 2006. 
[8] Health \& Safety Executive, EH40/2005 Workplace exposure limits, 2005.

[9] The European Standard EN 13779:2004 (E) Ventilation for non-residential buildings-performance requirements for ventilation and room-conditioning systems, $15^{\text {th }}$ October 2004.

[10] Dean J A. Lang's Handbook of Chemistry, 17th edition. 1979.

[11] BSRIA Technical Note 2/2002, Building-related Sickness Causes, effects, and ways to avoid it. Edited by Anu Palmer and Rosie Rawlings, 2002. 